\title{
Use and Management of Pesticides in Small Fruit Production
}

\author{
Carlos García Salazar¹, Anamaría Gómez Rodas² and John C. Wise² \\ ${ }^{1}$ Agriculture $\&$ Agribusiness Institute, \\ Michigan State University Extension, West Olive, MI \\ ${ }^{2}$ Department of Entomology, Trevor Nichols Research Center, Fennville, MI
}

USA

\section{Introduction}

Historically, pesticide management has been an inefficient process for pest control in tree fruit production. The amount of active ingredient released into the pest habitat is thousands of times greater than the amount of pesticide required to kill it if the treated population were confined in a jar or a small space. To illustrate this, lets take the oral LD50 for methyl parathion in rats $(18$ to $50 \mathrm{mg} / \mathrm{kg})(1,2)$ and the field dose for controlling the Brown Stink Bug (BSB) in pecans (Penncap-M, 227 grams of active ingredient (AI) per acre) (3). If the weight of the population of BSB in one acre of pecans were the equivalent of $1 \mathrm{~kg}$, taking the LD50 of 50 $\mathrm{mg} / \mathrm{kg}$ for methyl parathion we may need only $100 \mathrm{mg}$ to kill the entire population if treated in a jar or a small confined space. But since they are distributed all over the field it takes thousand times more product than needed to kill every insect present in the treated field.

In today's world, due to the increased cost of the pesticides a more efficient approach is needed, as well as more potent poisons requiring smaller application rates and new environmental legislations. In 1996, the enactment of the Food Quality Protection Act (FQPA) in the United States of America changed for good the way we controlled pests in agriculture in general (4). The enactment of the FQPA legislation demanded the reregistration of all pesticides used in agriculture until 1996. One of the major changes was the introduction of a $10 \mathrm{X}$ safety margin for children for pesticides shown to have a deleterious effect on children and woman during pregnancy.

The most important changes occurring under FQPA were that pesticides had to be evaluated in relation to the aggregated exposure taking into consideration all potential sources of exposures to residues in food, water and residential use. Pesticides with a common mode of action potential exposure had to be assessed as a cumulative exposure. Finally, potential risk must be assessed without considering the benefits.

Organophosphate (OP) or conventional insecticides used extensively in fruit production were some of the most affected by FQPA. This created the need for new chemicals to substitute those products that were removed from the list of approved materials. Products that were not cancelled required mitigation measures that restricted their use. These substitute pesticides are less effective and require multiple applications to obtain similar results than the ones obtained with conventional OP's. This difference in the performance of the new pesticides increased the cost of pest control. New products are more pest-specific, a 
small amount of a.i. is required per application $(<1 \mathrm{oz} /$ acre $)$ and intensive site-specific IPM pest scouting is required to effectively use them.

Under this new paradigm, an effective use and management of pesticides require growers and IPM practitioners to know the chemistry of the pesticide being used, the biology of the pest and its behavior, the influence of weather, plant structure, and equipment used to release the pesticide into the pest habitat.

\section{Problems associated with the use of pesticides in agriculture}

Every year there are a number of claims to farm insurance companies that are the result of errors during the application of pesticides. The main causes for losses of crops due to misapplications are equipment failure (24\%), improper tank mixes (33\%) and drift (33\%). Other causes are application in the wrong field and problems reading the label of the product (5). The most important main factors affecting the efficacy of pest control are, the prevailing weather conditions during the application, the type of nuzzles and conditions of the spray equipment, the characteristics of the crop and the behavior of the pest. Although the applicator can not control some of these factors there are always measures that may help reduce the pesticide environmental impact and increase their effectiveness.

\section{Weather conditions during the application}

Wind velocity. It is usually the most critical factor of all meteorological conditions affecting the efficacy of the pesticide application. The greater the wind speed, the farther off-target a droplet of a given size will be carried. The larger the droplet, the less it is affected by the wind and the faster it will fall. High winds however, can cause even larger droplets to move off-target. Therefore, spraying operations should be stopped if wind speeds are excessively high (> 10 miles/hour or $16 \mathrm{Km} /$ hour). In 2001, the US Environmental Protection Agency (EPA) issued a recommendation that indicated that for pesticide applications in orchards and vineyards and other fruit crops the maximum wind speed during the application should be between 3 and 10 miles/hour (4.5-16 Km/hour) (EPA 730-N-01-006). To illustrate the effect of wind velocity on pesticide droplets we may take the data from Rose and Lambi (1985) (6). They showed that droplets 100 microns in diameter travel $4.6 \mathrm{~m}$ in a wind speed of $1.6 \mathrm{Km}$ /hour. However, in a wind speed of $8 \mathrm{Km} /$ hour they travel $23.1 \mathrm{~m}$. A droplet of 400 microns under the same conditions travels 1 and $5 \mathrm{~m}$, respectively.

Relative Humidity. As droplets fall through the air, they evaporate into the atmosphere. This evaporation reduces the size and mass of the particle enabling it to remain airborne longer and, under the right conditions, to drift farther from the application site. The rate at which water evaporates from the spray particles depends primarily on air temperature and relative humidity. At $70 \%$ relative humidity and $78^{\circ} \mathrm{F}$, a 100 -micron droplet will fall 5 feet and hit the ground before evaporating to half its original diameter. However, at $30 \%$ relative humidity and $78^{\circ} \mathrm{F}$, a 100 -micron droplet quickly evaporates and becomes one-eighth of its original volume while falling only 2.5 feet. While evaporative loss of spray materials occurs under almost all atmospheric conditions, these losses are less pronounced under the environmental conditions that occur during the cooler parts of the day - early morning and late afternoon. The relative humidity is usually highest during these cooler periods (7). Atmospheric stability. It is an important factor influencing drift. Under normal (stable) meteorological conditions, the air temperature decreases by $5.4^{\circ} \mathrm{F}$ per 1,000 feet of height $\left(1^{\circ}\right.$ 
C per 100 meters). Cool air tends to sink, displacing lower warm air and causing vertical mixing. As a warm air layer rises, suspended droplets rise with it and dissipate into the upper layers by normal air turbulence and vertical mixing. Vertical mixing is the result of the ADIABATIC effect. Adiabatic effect refers to the behavior of a parcel of air when it moves up and down through a gradient of pressure in the atmosphere-this being greatest at the surface and diminishes with height. This process occurs as follows: Rising Air Parcel. This movement causes adiabatic cooling. As the air parcel rises it enters a low pressure region and this causes the parcel to expand. This sudden expansion causes a decrease in the parcel's temperature and it starts cooling down. This effect is similar to opening a canister of propane gas, while it escapes the gas forms a frosty cap at the tip of the exit. Falling Air Parcel. This creates the adiabatic warming. As the parcel of air starts falling down, it enters a region of high pressure. This change in atmospheric pressure compresses the parcel of air and causes an increase in its temperature. The parcel of air continues descending until its pressure and temperature equals the surrounding air (Figure 1).
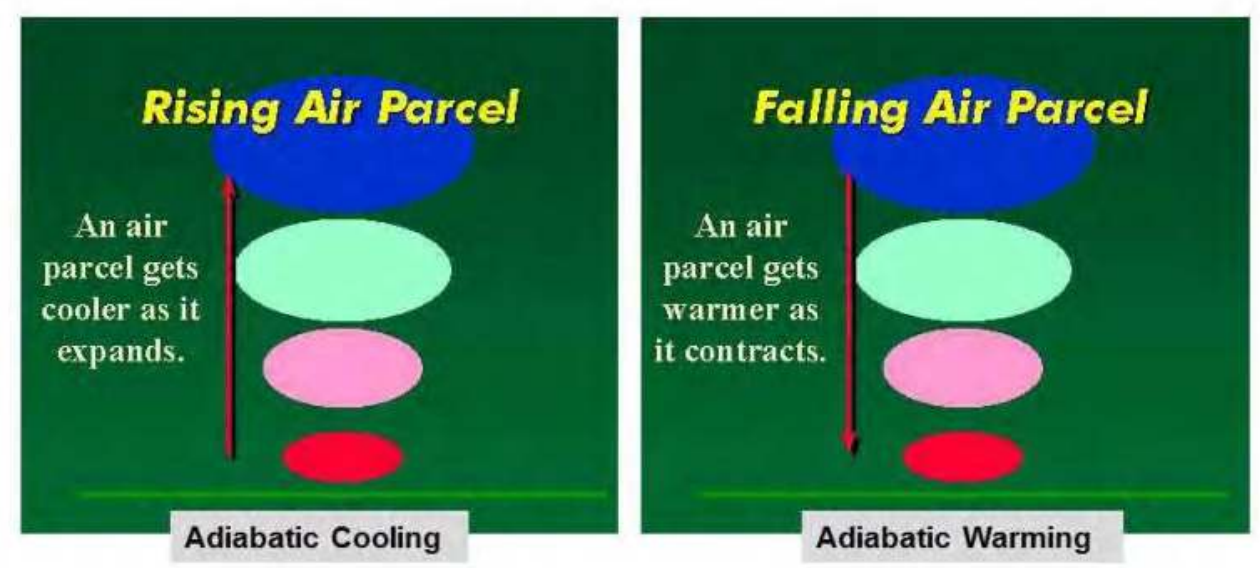

Fig. 1. Adiabatic effect.

When the rising parcel of air gets cooler than the surrounding air, it stops rising. This produces a situation in which the temperature at ground level and the temperature several hundred meters above the ground are the same. There is no vertical movement of the air and the atmosphere is in a condition of stability. Conversely, if the rising parcel gets warmer than the surrounding air, it continues rising creating the condition of atmospheric instability where parcels of air move up and down as they warm up and cool down.

Movement of pesticide droplets. When water-encapsulated pesticide droplets exit the nozzle their final deposition depends on the droplet size, the air and water temperature, and the environmental relative humidity. Big droplets (400-500 microns) will reach the foliage before losing substantial amount of volume. But all other droplets that do not reach the foliage are affected by the adiabatic effect. When those droplets are falling to the ground they are compressed by the atmosphere, their temperature rises beyond the surrounding air and they become airborne until their temperature equals the surrounding air. As those droplets cool down they fall back and the process is repeated again (Figure 2). 


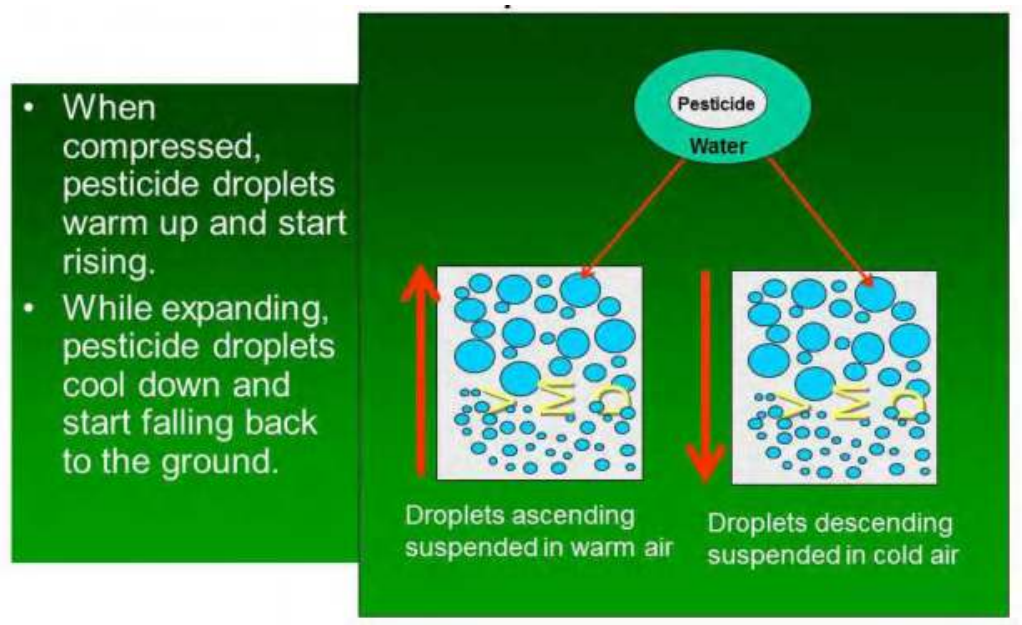

Fig. 2. Adiabatic effect on droplets containing the pesticides as they exit the nuzzle.

\section{Spray application under unstable conditions}

As warm air rises, suspended droplets rise with it and dissipate into the upper layers by normal air turbulence and vertical mixing. Under these conditions, the opportunity for crop injury at any specific off target site is very small because the pesticide is dispersed and diluted into the atmosphere. Figure 3, shows the application with a cannon sprayer in blueberries under unstable conditions. The picture shows that most of the drift remains confined to the first 5-6 rows facing the sprayer and the cloud of droplets that constituted drift moves up with little horizontal movement out of the target area

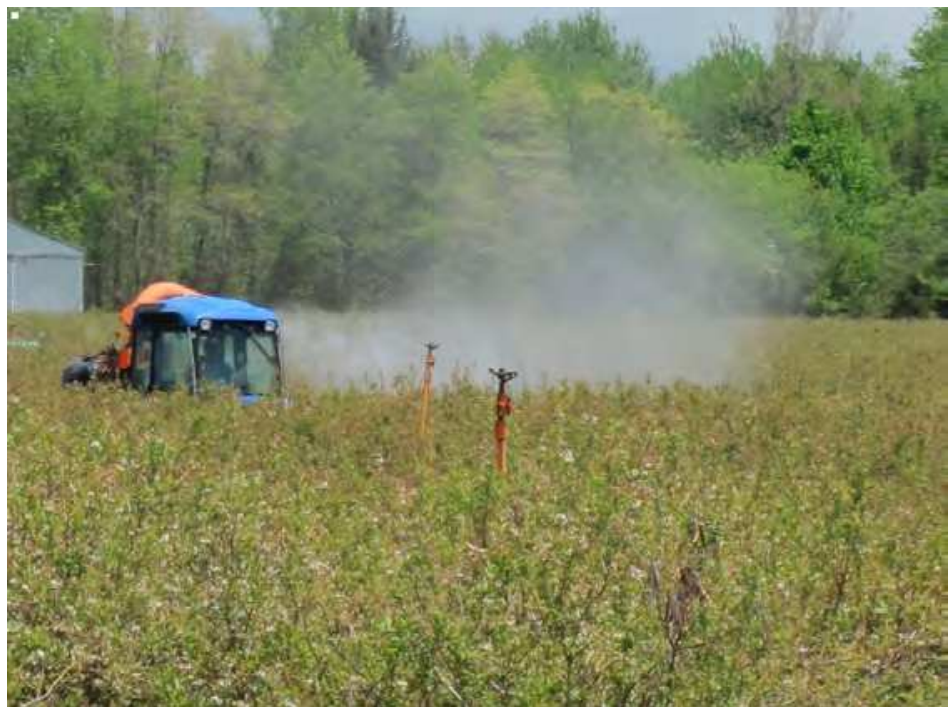

Fig. 3. Spray application under unstable conditions in a blueberry field. 


\section{Spray application under stable conditions}

Under stable air conditions since the temperature at ground level is the same over the next few hundred meters above the ground, vertical air movement is hindered and there is little or no atmospheric mixing. Consequently, fine droplets will hang in the air and slowly diffuse superficially on relatively level terrain.

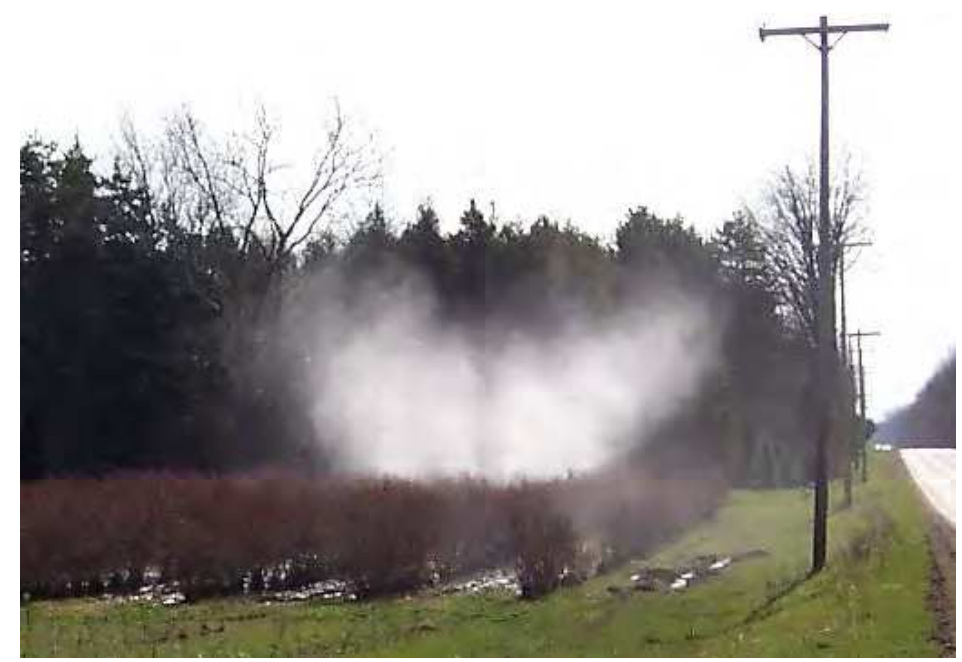

Fig. 4. Spray application early in the morning with no vertical mixing.

In Figure 4 the effect of atmospheric stability is presented. Fine spray droplets remain aloft traveling horizontally away from the target area. In this picture, pesticide drift goes over the road falling on passing by vehicles. Applications under these circumstances are the most problematic because they cause dangerous drifts that end up creating environmental pollution.

A very common type of atmospheric stability is the one created by an inversion of the gradient of temperature occurring in the atmosphere. Under conditions of instability the air temperature decreases with an increase in altitude, $5.4^{\circ} \mathrm{F}$ per 1,000 feet of height $\left(1^{\circ} \mathrm{C}\right.$ per 100 meters, approximately). Very often the air temperature near the ground is cooler than the air a few meters above ground; the surrounding air gets warmer with increasing altitude. This creates a layer of hot air that acts like a cap that does not allow the vertical movement of the air holding down cooler air underneath. This phenomenon is what we call thermal inversion and is very frequent very early in the morning and during the evening hours when the ground cools the air layer immediately above it.

Spray application under thermal inversion conditions. Pesticide applications conducted under conditions of thermal inversion are prone to produce large quantities of dangerous drifts. Pesticide particles suspended in the cool layer cannot move anywhere except laterally, possibly for several miles. Do not spray during thermal inversions, when air close to the ground is colder than the air above it. You should not spray early in the morning in still air if sensitive areas are nearby (especially down gradient if the terrain is sloped). Applicators concerned about these adverse spraying conditions should wait until late 
afternoon or early evening to spray, when there is less chance of the atmosphere being inverted and conditions are more favorable.

\section{Spray equipment used for pesticide applications in small fruit crops}

The most important factor in providing an efficient pesticide cover is type of equipment. The efficacy of your pest control depends on the right selection of your spraying equipment. Different types of spraying equipment are used in small fruit crops for pest control. Airblast spraying equipment is the most common equipment employed for pesticide application (Figure 5).

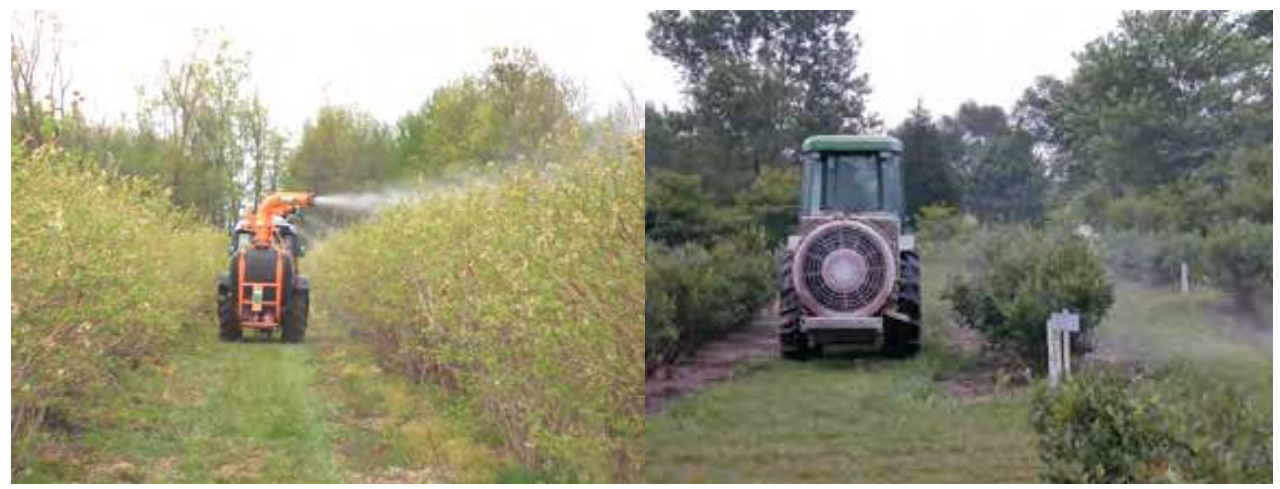

Fig. 5. Air assisted sprayers: right, a cannon sprayer; left, conventional air-blast sprayer.

However, when the crop canopy makes it difficult to apply pesticides using ground equipment fixed-wing aircrafts are mainly used (Figure 6).

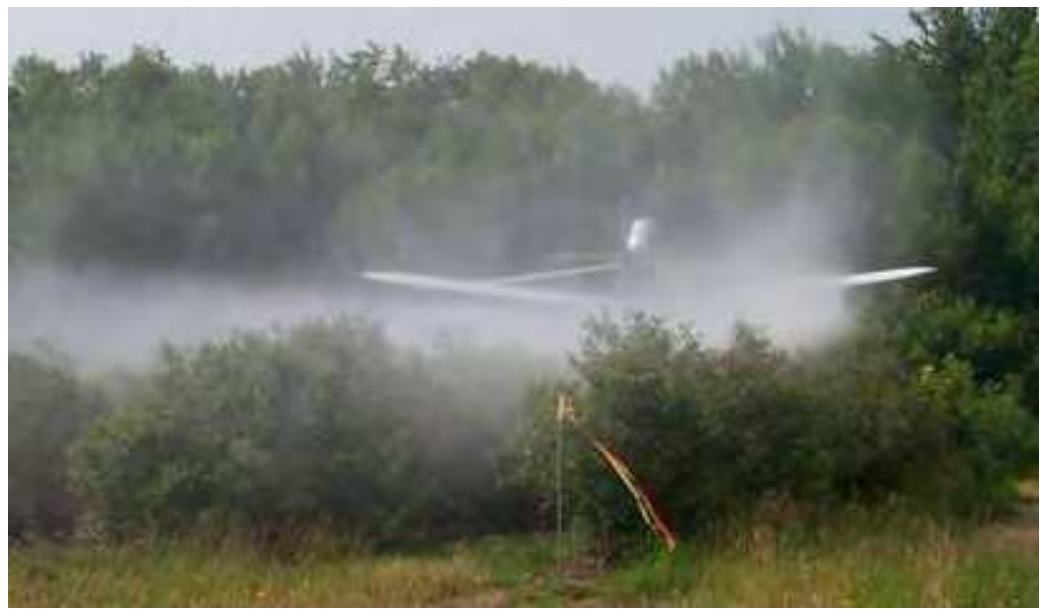

Fig. 6. Aerial application of insecticide in blueberries near harvest with fixed-wing aircrafts (Fennville, Michigan 2006). 
Different air-assisted equipment produces different types of spray which in turn have different distribution on the target crop. Table 1 shows the properties of different airassisted equipment on the deposition of pesticides on the target canopy.

\begin{tabular}{|c|c|c|c|}
\hline $\begin{array}{c}\text { Application } \\
\text { Technology }\end{array}$ & Droplet size & Canopy Penetration & Field Distribution \\
\hline Air-blast Sprayer & $\begin{array}{c}\text { Fine - Very } \\
\text { Coarse }\end{array}$ & High & Uniform \\
\hline Cannon Sprayer & $\begin{array}{c}\text { Very Fine - } \\
\text { Medium }\end{array}$ & Medium & $\begin{array}{c}\text { Horizontally- } \\
\text { Variable }\end{array}$ \\
\hline Aerial Application & Fine - Medium & Medium & Vertically Variable \\
\hline Proptec Sprayer & Fine - Medium & High & Uniform \\
\hline
\end{tabular}

Table 1. Pesticide application equipment and characteristics of spray deposition.

Show (1996) gave a very good definition of every type of spray depending on the droplet size (5). Accordingly, a very fine spray (VF) is made of droplets with a diameter < 182 microns $(\mu \mathrm{m})$; A fine spray $(\mathrm{F})$ is made of droplets with a diameter ranging from 183 to 280 $\mu \mathrm{m}$; Medium spray (M) is made of droplets ranging from 281 to $429 \mu \mathrm{m}$; A coarse spray (C) is made of droplets ranging from 430 to $531 \mu \mathrm{m}$ in diameter, etc.

The type of spray produced by the equipment determines the volume of water needed to spray the recommended dose of pesticide. The following table indicates how much water is needed to cover one acre of blueberries using different types of sprays.

\begin{tabular}{|c|c|c|c|}
\hline Spray type & Volume type & $\begin{array}{c}\text { Droplet diameter } \\
(\mu \mathrm{m})\end{array}$ & $\begin{array}{c}\text { Application rate } \\
\text { gal/acre }\end{array}$ \\
\hline Coarse & High & 500 & 108 \\
\hline Medium & Medium & $200-500$ & $32-108$ \\
\hline Fine & Low & $100-200$ & $6-32$ \\
\hline
\end{tabular}

Table 2. Type of spray and its effect on the amount of water needed to spray one acre of blueberries.

\section{Plant structure and canopy: where do your chemicals end up?}

After selecting the right environmental conditions and the equipment for the spray application the next factors determining the success of your applications will be, type of canopy and plant structure.

Plant structure is important in determining the final destination of your spray. It also influences the success of pest control. Canopy is the place where the pest is found scouting for food, mating, looking for oviposition sites or escaping from natural enemies and adverse environmental factors. This also includes escaping from the applications of pesticides. Therefore, in determining the amount of water and the equipment required to control a pest problem, type of target crop and plant structure are crucial.

In blueberries, for example, the structure of the bush is important in the efficacy of the application of insecticides and fungicides using air blast sprayers. A well pruned bush will allow for better penetration of the pesticide. Thus, you could achieve better pest control and 
savings in product. On the other hand, thick canopies prevent the placement of the product in the habitat of the pest resulting in poor and more expensive pest control. Van Ee et al.(2000) demonstrated how different types of pruning affected pesticide deposition in "highbush" blueberries (Vaccinium coymbosnm L) at different times during the plant growth season. Their goal was to determine how sprayer type, pruning severity, and canopy development interacted to affect spray deposition patterns. Deposition was measured as the percentage of the surface area of card targets that was covered following applications of black dye. Light measurements indicated that the canopy of blueberry bushes, regardless of pruning treatment, closed by the middle of June, and light levels within the canopy changed little from then until fruit harvest in August. They used a standard airblast sprayer that pushed spray up and white kromcoat cards clipped to each target. Targets were clipped to branches in a random orientation in the same two bushes used for the light measurements. Figures 7.1, 7.2, and 7.3 showed the conditions of pruning of treated bushed before treatments were applied.

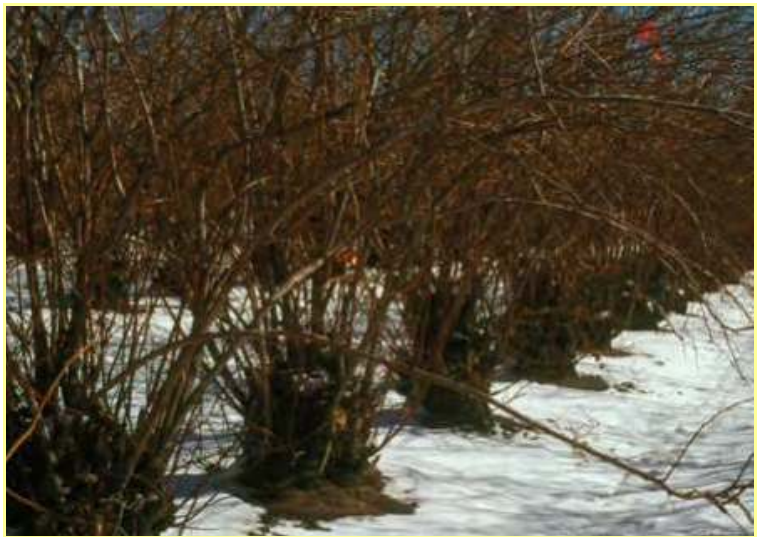

Fig. 7.1. Lightly pruned bushes.

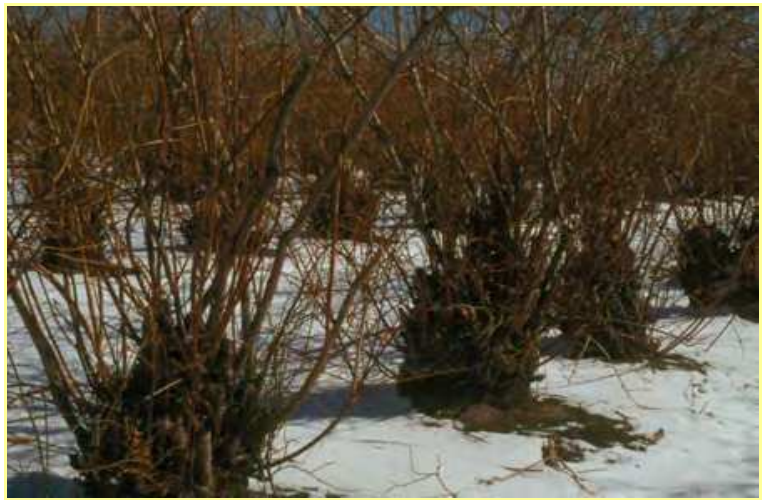

Fig. 7.2. Moderately pruned bushes. 


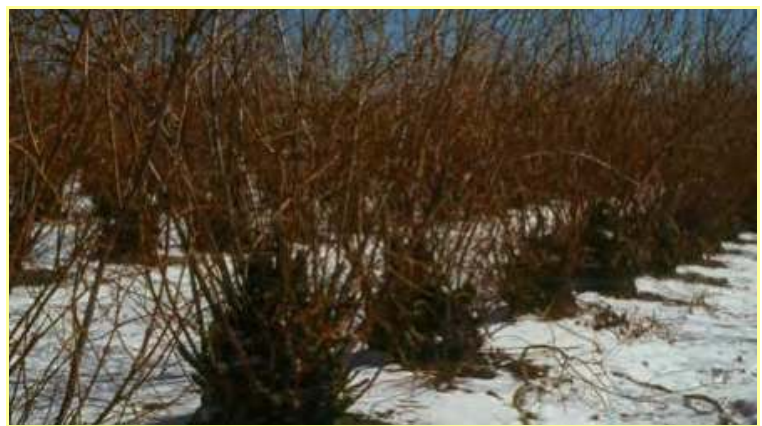

Fig. 7.3. Heavily pruned bushes.

Van Ee, found that spray penetration and deposition in all types of canopies was greater in the bush's side facing the sprayer. However, spray penetration and coverage was greatly reduced at the far side of the bush when the field was lightly pruned. Conversely, medium or heavy pruning allowed more penetration and deposition than in light pruned bushes. Moderate or heavy pruning allowed similar deposition, except at the top of the bush. In the heavily pruned bushes pesticide deposition was greater than at any other canopy structure (7.3).

In 2006, we conducted a study to determine the spray deposition patterns in mature blueberries using different spray equipment. A mature Jersey field was sprayed with Surround WP (kaolin clay) utilizing a cannon sprayer, an airblast sprayer and a 20-gallon aerial application (Wise et al. unpublished results).

We found that a spray application of $50 \mathrm{gal} /$ acre in light pruned bushes resulted in high deposition at the bottom and middle portion of the canopy and less deposition on the top of the bush. The same volume applied with a cannon sprayer resulted in higher spray deposition on top of the bush but less deposition on the middle section and much less at the bottom of the bush.

The application of a spray volume of 20 gallons to the same field with fixed-wing aircraft resulted in an even deposition of the spray from top to bottom of the bush.

These results were very important to establish what type of equipment we need to use to apply pesticides in blueberry fields in order to optimize the efficacy of the pesticide.

\section{Pest habitat and behavior}

Finally, the purpose of the spray application is to place the pesticide in contact with the pest. This objective can be achieved in two ways; 1 ) depositing the pesticide in the habitat of the pest were the pest may enter in contact with the pesticide or 2) placing the pesticide in contact with the pest by taking advantage of its behavior. In this case the pest "finds" the product while moving around the canopy of the crop.

For plant diseases and insects that do not move a lot and remain confined to a small area (a leaf, branch, bush or section of the canopy) we need to bring the pesticide to the pest by targeting their habitat. Spray cover has to be very good with enough number of droplets per square centimeter of foliage to maximize the probability of the pest getting in contact with the spray. In the case of blueberry aphids and fruitworms, pest control measures require placing the insecticide in the habitat of the pest. Blueberry aphids live at the bottom, inside 
of the bush. Thus, spray applications should reach the bottom of the bush. If the product applied is systemic, droplet size does not really matter, the product will be translocated into de plant and the insect will acquire the lethal dose while sucking up sap. With the Cranberry fruitworm (Acrobasis vaccinii Riley) and the Cherry fruitworm (Grapholita packardi Zeller), if pest control is directed against eggs and larvae it should be directed into the calyx of the fruit. The product needs to be placed also into the calyx where larvae will hatch. In this case a large volume of spray needs to be deposited on the top of the blueberry bush where the fruit is produced and the fruitworms mate and deposit their eggs. In both cases, a large number of small droplets of pesticide need to be applied into the habitat of the insect.

With an insect or pest that moves a lot or explores intensively the canopy of the crop, like the Blueberry Maggot (Rhagoletis mendex) or the Cranberry fruitworm first instar larvae. A few large droplets will be enough to have a good control of these pests. Adult blueberry maggot explores intensively the blueberry canopy in search of mates, food and sites to oviposit. Also, first instar Cranberry fruitworm larvae after hatching crawl out of the berry calix to search for a place to enter the berry at the site where the peduncle and the fruit meet. In both insects the wandering period is critical to put the pesticide in contact with the pest. Table 3 presents a summary of the habitat and behavior of several insects that attack blueberries in Michigan.

\begin{tabular}{|c|c|c|c|c|}
\hline Pest & $\begin{array}{c}\text { Targeted Life } \\
\text { Stage }\end{array}$ & $\begin{array}{c}\text { Pest Behavioral } \\
\text { Activity Level }\end{array}$ & $\begin{array}{c}\text { Location on the } \\
\text { Plant }\end{array}$ & Exposure Period \\
\hline Fruitworms & Egg/larva & Low & Fruit Cluster & Short \\
\hline Leafrollers & Larva & Medium & Upper Canopy & Long \\
\hline $\begin{array}{c}\text { Blueberry } \\
\text { Maggot }\end{array}$ & Adult & High & Upper Canopy & Short \\
\hline $\begin{array}{c}\text { Japanese Beetle } \\
\text { Alueberry Aphid }\end{array}$ & Adult/Nymphs & Low & Lower Canopy & Long \\
\hline Bud mites & Adult/Nymphs & Low & Buds & Short \\
\hline
\end{tabular}

Table 3. Habitat and behavior of several insect pest of "Highbush" blueberries.

\section{Pesticide management summary}

We can summarize the recommendations for optimizing the efficacy of the pesticides as follow:

The pesticide efficacy and efficiency will depend on:

Weather conditions that affect the movement of pesticides in the environment.

- Avoid spraying under low relative humidity,

- Avoid spraying when wind speed is greater than $10 \mathrm{mph}$, 
- $\quad$ Avoid spraying under stable or thermal inversion conditions

Equipment. This affects pesticide deposition in the target site (amount of product and percentage of surface area covered).

- Use the appropriate spraying equipment,

- Calibrate your sprayer,

- Use the appropriate spray volume.

The conditions of the sprayer will limit the biological effect of the spray. Important factors to consider are droplet size, volume and distribution of the application

Crop conditions. This affects the penetration of chemicals and pesticide deposition. Proper pruning facilitates:

- $\quad$ spray penetration and deposition,

- $\quad$ and placement of the pesticide into the pest habitat,

- $\quad$ removes refuge sites where the pest can find shelter.

In the case of crop conditions, the canopy density limits the spray's penetration and deposition. It will be more difficult to implement a successful pesticide management program in a slightly pruned field than in a field that is properly pruned. A thick canopy provides many places where the pest can be protected from natural enemies and from our pesticides! Under these circumstances, only a limited amount of our spray will reach the pest habitat limiting the effectiveness of our pest control program.

Pest behavior. Each pest species has its particular behavior. Therefore, the efficacy of your pest control will depend on:

- your understanding of the pest biology and behavior,

- $\quad$ the behavior of a pest that limits the critical window to control it

Knowing the pest is important because it is the objective of our pest control program. If we do not understand the pest biology and behavior, chances are we will miss the critical times when the pest is more susceptible to our pesticides.

Finally, the success of your Pesticide management program will depend on your ability in putting the pesticide in contact with the pest either by:

- Placing the pesticide in the pest habitat and/or,

- Taking advantage of the pest behavior

\section{References}

[1] Hayes, W.J. and E.R. Laws (ed.). 1990. Handbook of Pesticide Toxicology, Vol. 3, Classes of Pesticides. Academic Press, Inc., NY.

[2] Meister, R.T. (ed.). 1992. Farm Chemicals Handbook '92. Meister Publishing Company, Willoughby, $\mathrm{OH}$.

[3] Crop Data Management Systems, Inc. 2007. PennCap-M. http://www.cdms.net/LDat/ld403009.pdf

[4] U.S. Food and Drug Administration. 2009. The Food Quality Protection Act of 1996. http://www.fda.gov/RegulatoryInformation/Legislation/FederalFoodDrugandC osmeticActFDCAct/SignificantAmendmentstotheFDCAct/ucm148008.htm.

[5] Show, B.W. 1996. Minimizing Spray Drift. Texas Agricultural Extension Service, The Texas A\&M University System. College Station, Texas. agsafety.tamu.edu/Programs/Ag-Chemical/drift.ppt 
[6] Ross, Merrill A. and Carole A. Lembi. 1985. Applied Weed Science. Burgess Publishing Company, Minneapolis, MN.

[7] H. Erdal Ozkan. 1998. Effect of Major Variables on Drift Distances of Spray Droplets. The Ohio State University Extension (AEX-525-98). http://ohioline.osu.edu/aexfact/0525.html.

[8] Van Ee, G., Richard Ledebuhr, Eric Hanson, Jim Hancock, and Donald Ramsdell (2000) Canopy Development and Spray Deposition in Highbush Blueberry. HortTechnology 10(2) 354-357. 


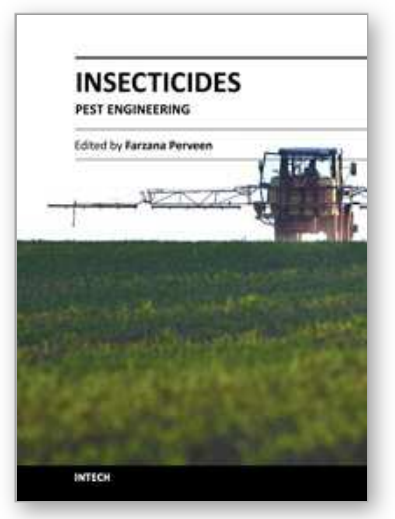

\author{
Insecticides - Pest Engineering \\ Edited by Dr. Farzana Perveen
}

ISBN 978-953-307-895-3

Hard cover, 538 pages

Publisher InTech

Published online 15, February, 2012

Published in print edition February, 2012

This book is compiled of 24 Chapters divided into 4 Sections. Section A focuses on toxicity of organic and inorganic insecticides, organophosphorus insecticides, toxicity of fenitrothion and permethrin, and dichlorodiphenyltrichloroethane (DDT). Section B is dedicated to vector control using insecticides, biological control of mosquito larvae by Bacillus thuringiensis, metabolism of pyrethroids by mosquito cytochrome P40 susceptibility status of Aedes aegypti, etc. Section $C$ describes bioactive natural products from sapindacea, management of potato pests, flower thrips, mango mealy bug, pear psylla, grapes pests, small fruit production, boll weevil and tsetse fly using insecticides. Section $D$ provides information on insecticide resistance in natural population of malaria vector, role of Anopheles gambiae P450 cytochrome, genetic toxicological profile of carbofuran and pirimicarp carbamic insecticides, etc. The subject matter in this book should attract the reader's concern to support rational decisions regarding the use of pesticides.

\title{
How to reference
}

In order to correctly reference this scholarly work, feel free to copy and paste the following:

Carlos García Salazar, Anamaría Gómez Rodas and John C. Wise (2012). Use and Management of Pesticides in Small Fruit Production, Insecticides - Pest Engineering, Dr. Farzana Perveen (Ed.), ISBN: 978-953-307-8953, InTech, Available from: http://www.intechopen.com/books/insecticides-pest-engineering/use-andmanagement-of-pesticides-in-small-fruit-production

\section{INTECH}

open science | open minds

\author{
InTech Europe \\ University Campus STeP Ri \\ Slavka Krautzeka 83/A \\ 51000 Rijeka, Croatia \\ Phone: +385 (51) 770447 \\ Fax: +385 (51) 686166 \\ www.intechopen.com
}

\author{
InTech China \\ Unit 405, Office Block, Hotel Equatorial Shanghai \\ No.65, Yan An Road (West), Shanghai, 200040, China \\ 中国上海市延安西路65号上海国际贵都大饭店办公楼 405 单元 \\ Phone: +86-21-62489820 \\ Fax: $+86-21-62489821$
}


(C) 2012 The Author(s). Licensee IntechOpen. This is an open access article distributed under the terms of the Creative Commons Attribution 3.0 License, which permits unrestricted use, distribution, and reproduction in any medium, provided the original work is properly cited. 